trình điều trị.

Đối với xạ trị, việc điều trị hạn chế ngoại trừ những trường hợp chửa trứng xâm nhập có di căn não, mặc dù hiệu quả của xạ trị so với điều trị bằng Methotrexate còn nhiêu tranh cãi.

Trường hợp bệnh nhân của chúng tôi được phẫu thuật trước, sau phẫu thuật BHCG giảm mạnh (Từ 1033000U/L xuống còn 1320U/L). Sau điểu trị hóa chất 4 chu kỳ với Methotrexat, BHCG đã giảm dần về mức bình thường $<5 \mathrm{U} / \mathrm{L}$ (Biểu đồ 1 ). Kết quả cho thấy bệnh nhân đáp ứng tốt với điều trị hóa chất.

\section{KẾT LUÂ̂N}

Chửa trứng xâm nhập là bệnh lý của nguyên bào nuôi hiếm gặp ở tuổi tiền mãn kinh và mãn kinh, xâm nhập và phá hủy tại tử cung và có thể di căn xa. Bênh có tiên lượng tốt do đáp ứng tốt với điều trị hóa chất. Ca bệnh chúng tôi báo cáo là chửa trứng xâm nhập ở tuổi 55 , chưa có di căn. Sau phẫu thuật và điều trị hóa chất cho đáp ứng tốt, BHCG giảm dần về mức bình thường. Tuy nhiên, bệnh nhân vẫn cần được theo dõi định kỳ.

\section{TÀI LIÊU THAM KHẢO}

1. Altieri A, Franceschi S, Ferlay J, Smith J, La Vecchia C. Epidemiology and aetiology of gestational trophoblastic diseases. The Lancet. Oncology. Nov 2003;4(11):670-678.

2. Martinez Leocadio C, Garcia Villayzan J, Garcia-Foncillas Lopez J, Idrovo F, Plaza Arranz J, Albi Gonzalez M. Invasive mole in a perimenopausal woman with lung and vaginal metastases: A case report. Clinical case reports. Dec 2019;7(12):2300-2305.
3. Tsukamoto $\mathbf{N}$, Iwasaka $\mathbf{T}$, Kashimura $\mathbf{Y}$, Uchino $\mathbf{H}$, Kashimura $M$, Matsuyama $\mathrm{T}^{\prime}$. Gestational trophoblastic disease in women aged 50 or more. Gynecologic oncology. Jan 1985;20(1):53-61.

4. Ismail S, Mikhael $K$, Salloum N, Alshehabi $Z$. An invasive mole with pulmonary metastases in a 55-year-old postmenopausal Syrian woman: a case report and review of the literature. Journal of medical case reports. Jan 18 2021;15(1):13.

5. de la Fouchardiere A, Cassignol A, Benkiran L, Rudigoz RC, Gougeon A, DevouassouxShisheboran M. [Invasive hydatiform mole in a postmenopausal woman]. Annales de pathologie. Oct 2003;23(5):443-446.

6. Taskin S, Cengiz B, Ortac F. Invasive mole in a postmenopausal woman. International journal of gynaecology and obstetrics: the official organ of the International Federation of Gynaecology and Obstetrics. May 2006;93(2):156-157.

7. von Welser SF, Grube M, Ortmann O. Invasive mole in a perimenopausal woman: a case report and systematic review. Archives of gynecology and obstetrics. Dec 2015;292(6):1193-1199.

8. Akyol A, Simsek M, Ucer 0 . Giant invasive mole presenting as a cause of abdominopelvic mass in a perimenopausal woman: An unusual presentation of a rare pathology. Obstetrics \& gynecology science. Nov 2016;59(6):548-553.

9. Nakashima A, Miyoshi A, Miyatake $T$, Kazuhide 0, Takeshi Y. Perimenopausal invasive hyadatidiform mole treated by total abdominal hysterectomy followed by chemotherapy. Journal of surgical case reports. Sep 20 2016;2016(9).

10. Ngan HYS, Seckl MJ, Berkowitz RS, et al. Update on the diagnosis and management of gestational trophoblastic disease. International journal of gynaecology and obstetrics: the official organ of the International Federation of Gynaecology and Obstetrics. Oct 2018;143 Suppl 2:79-85.

\title{
NGHIÊN CỨU TÌNH HÌNH BÊNH LÝ VIÊM TAI Ứ DICH LỨA TUỔI MẪU GIÁO NHÀ TRẺ TẠI XÃ QUỐC TUẤN HUYỆN AN DƯƠNG HẢI PHÒNG
}

\section{TÓM TẮT}

Mục tiêu: Mô tả tình trạng bệnh lý viêm tai ứ dịch của trẻ em lứa tuổi mẫu giáo, nhà trẻ và tìm một số yếu tố liên quan đến bệnh lý viêm tai ứ dịch ở trẻ em. Đối tượng và phương pháp: nghiên cứu mô tả cắt ngang trên 476 trẻ độ tuổi mẫu giáo, nhà trẻ tại xã Quốc Tuấn, Huyện An Dương, Hải Phòng. Kết quả:

*Đại học Y Dược Hải Phòng

Chịu trách nhiệm chính: Ta Hùng Sơn

Email: dr.hungson@gmail.com

Ngày nhận bài: 17.9.2021

Ngày phản biện khoa họ: 15.11.2021

Ngày duyệt bài: 24.11.2021
Tạ Hùng Sơn*

viêm tai ứ dịch chiếm tỉ lệ $4,2 \%$ số trẻ, bệnh gặp nhiều hơn ở giới, tuổi dưới 3 tuổi, số người trong gia đình nhiều hơn 4 , tiền sử sinh nhe cân dưới $2,8 \mathrm{~kg}$, tân suất viêm mũi họng lớn (<2 tháng/lần); trẻ bị V.A Amiđan quá phát. Chưa thấy mối tương quan về thứ tự sinh, tiên sử nuôi dưỡng bằng sữa mè, tiên sử bệnh dị ứng với nguy cơ mắc bệnh. Kết luần: Viêm tai ứ dịch là một bệnh thường gặp ở trẻ em lứa tuổi nhà trẻ mấu giáo, yếu tố nguy cơ thường gặp là giới nam, tiền sử sinh nhe cân, tuổi nhỏ, mât độ người cùng chung sống đông, thường xuyên bị tái phát viêm mũi họng và mắc các bệnh lý V.A - Amiđan quá phát.

Từ khóa: viêm tai ứ dịch, yếu tố nguy cơ, trẻ em

\section{SUMMARY}

PREVALENCE AND RISK FACTORS OF 


\section{OTITIS MEDIA WITH EFFUSION IN KINDERGARTEN AGE RANGE IN QUOCTUAN COMMUNE - ANDUONG DISTRICT - HAIPHONG}

Objectives: Prevalence and risk factors of otitis media with effusion in kindergarten age range. Study design: a cross-sectional study. Results Prevalence of OME reaches $4,2 \%$ in kindergarten age range. Prevalence is higher in male, age less than 3 years, family size more than 4 members in the household, low birth weight less than $2,8 \mathrm{~kg}$, frequency nasopharyngitis higher ( $<2$ months / time); adenoids - tonsils hypertrophic. No significant correlation was found between OME and type of feeding during the first six months of life, birth order, allergic history. Conclusion : OME is common disease in kindergarten age range. Risk factor are history of low birth weight, small age, big family size, often recurent nasopharyngitis, adenoids - tonsils hypertrophic

Key words: $\mathrm{OME}$, risk factor, children

\section{I. ĐĂT VẤN ĐỀ}

Viêm tai giữa là một vấn đề sức khỏe nghiêm trọng và xảy ra với một tỷ lệ cao và phổ biến ở cả các nước phát triển và đang phát triển. Viêm tai giữa cấp và viêm tai ứ dịch là bệnh thông thường của trẻ và có thể tiến triển thành viêm tai giữa mạn tính. Mặc dù việc sử dụng kháng sinh để điều trị chỉ làm giảm số lượng các ca viêm tai giữa cấp và các biến chứng cấp tính, còn bệnh lý viêm tai ứ dịch lại thường bị bỏ quên và tỉ lệ chuyển biến mãn tính dường như ngày một tăng tăng. Hiểu biết về dịch tễ học và các yếu tố nguy cơ của viêm tai giữa ứ dịch có thể tạo điều kiện phát triển các chiến lược can thiệp và quản lý bệnh tốt hơn.

Do đó,chúng tôi tiến hành nghiên cứu này với hai muc tiêu sau:

1-Mô tả tình trạng bệnh lý viêm tai ứ dịch của trẻ em lúa tuổi mẩu giáo, nhà trẻ tại xã Quốc Tuấn, An Dương, Hải Phòng.

2- Tìm một số yếu tố liên quan đến bệnh lý viêm tai ứ dịch ở trẻ em.

\section{II. ĐỐI TƯợNG VÀ PHƯƠNG PHÁP NGHIÊN CỨU}

2.1. Đối tượng nghiên cứu. Gồm 476 trẻ lứa tuổi mẫu giáo nhà trẻ tại xã Quốc Tuấn - AN Dương - Hải Phòng

2.2. Phương pháp nghiên cứu. Nghiên cứu mô tả cắt ngang.

- Chỉ tiêu nghiên cứu: các đặc điểm lâm sàng ở bệnh nhân viêm tai ứ dịch, tỉ lệ các yếu tố nguy cơ, tìm mối liên quan yếu tố nguy cơ và tỉ lệ bệnh.

- Kỹ thuật thu thâp số liệu: Trẻ được khám, nội soi tai chẩn đoán, hỏi tiền sử khai thác các yếu tố nguy cơ
- Xử lý số liệu: theo phương pháp thống kê $y$ học, sử dụng phần mềm SPSS 18.0.

- Thời gian nghiên cứu: tháng 12 năm 2015.

\section{KẾT QUẢ NGHIÊN CỨU VÀ BÀN LUÂ̂N}

\subsection{Tỉ lệ bệnh và các yếu tố liên quan}

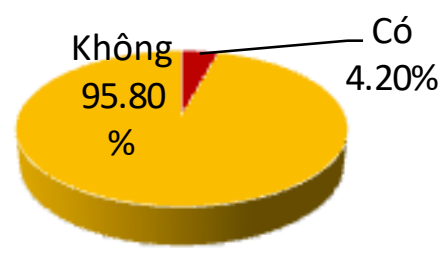

\section{Biểu đồ 1: Tỉ lệ bênh viêm tai ứ dịch}

Nhân xét: Tỉ lệ bệnh viêm tai ứ dịch gặp ở nhóm tuổi mẫu giáo, nhà trẻ là $4,2 \%$. Tỉ lệ này có thấp hơn so với một số tác giả nghiên cứu trước đây như Nguyễn THị Hoài An là 8,98\%

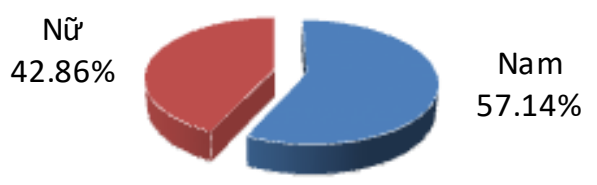

\section{Biểu đồ 2: Tỉ lê giới}

Nhận xét: tî lệ nam/ nữ trong nghiên cứu là gần như nhau.

Bảng 1: Số người trong gia đình

\begin{tabular}{|c|c|c|c|}
\hline & $\mathbf{S 4}$ & $\mathbf{> 4}$ & Tống \\
\hline $\mathrm{n}$ & 436 & 40 & 476 \\
\hline$\%$ & 91,60 & 8,40 & 100 \\
\hline
\end{tabular}

Nhân xét: phần lớn mô hình gia đình tai đây là gia đình 4 người, điều này phù hợp với đặc điếm của mô hình khu công nghiệp có đông các gia đình trẻ.

Bảng 2: Các yêu tố về tiền sử sinh và nuôi dưỡng

\begin{tabular}{|c|c|c|c|}
\hline \multicolumn{2}{|c|}{ nom } & \multirow{2}{*}{$\begin{array}{c}\mathbf{n} \\
464\end{array}$} & \multirow{2}{*}{$\begin{array}{c}\text { \% } \\
97,48 \\
\end{array}$} \\
\hline Tiền sử & Đủ tháng & & \\
\hline sinh & Thiếu tháng & 12 & 2,52 \\
\hline \multirow{2}{*}{$\begin{array}{l}\text { Cân năng } \\
\text { khi sinh }\end{array}$} & $\geq 2800 \mathrm{~g}$ & 416 & 87,39 \\
\hline & $<2800 \mathrm{~g}$ & 60 & 12,61 \\
\hline \multirow{2}{*}{$\begin{array}{c}\text { Tiền sử } \\
\text { nuôi } \\
\text { dưỡng } 6 \\
\text { tháng đâu }\end{array}$} & $\begin{array}{l}\text { Sữa mẹ hoàn } \\
\text { toàn }\end{array}$ & 382 & 25 \\
\hline & $\begin{array}{l}\text { Sữa công thức } \\
\text { hoặc hỗn hợp }\end{array}$ & 94 & 19,75 \\
\hline
\end{tabular}

Nhấn xét: đa số trẻ đều sinh đủ tháng đủ cân và được nuôi dưỡng hoàn toàn bằng sữa mẹ, điều này thể hiện y tế cơ sở đã làm tốt công tác quản lý thai nghén và tư vấn dinh dưỡng cho trẻ. 


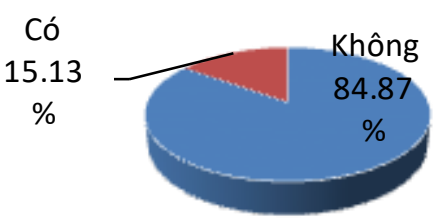

Biểu đồ 2: tiền sử các bênh dị ứng

Nhận xét: tỉ lệ trẻ mắc các bệnh về dị ứng là khá cao, chiếm 15,13\%

Bảng 3: Tiếp xúc với khói thuốc

\begin{tabular}{|c|c|c|c|}
\hline & $\begin{array}{c}\text { Thường } \\
\text { xuyên }\end{array}$ & $\begin{array}{c}\text { Thỉnh thoảng } \\
\text { hoặc không }\end{array}$ & Tổng \\
\hline $\mathbf{n}$ & 62 & 414 & 476 \\
\hline$\%$ & 13,03 & 86,97 & 100 \\
\hline
\end{tabular}

Nhâan xét: phân lớn bố mẹ trẻ đã ý thức được tác hại của khói thuốc với con trẻ nên tỉ lệ trẻ phải chịu tác động thường xuyên của khói thuốc thấp chỉ có $13,03 \%$

Bảng 4: Tần suất viêm mũi họng

\begin{tabular}{|c|c|c|c|c|}
\hline & $\begin{array}{c}\text { Dưới 2 } \\
\text { tháng/lần }\end{array}$ & $\begin{array}{c}\text { Tứ 2-6 } \\
\text { tháng/lần }\end{array}$ & $\begin{array}{c}\text { Trền 6 } \\
\text { tháng/lân }\end{array}$ & Tổng \\
\hline $\mathrm{n}$ & 160 & 294 & 22 & 476 \\
\hline$\%$ & 33,61 & 61,76 & 4,62 & 100 \\
\hline
\end{tabular}

Nhận xét: đa số trẻ thường xuyên bị viêm mũi họng với tần suất trung bình là 5-6 lần/năm. Điều này cũng phù hợp với quá trình phát triển về cơ quan miễn dịch của trẻ cũng như điều kiện chăm sóc trẻ tại địa phương.

Bảng 5: Bệnh mũi họng mạn tính

\begin{tabular}{|c|c|c|c|}
\hline & $\begin{array}{c}\text { Có (Viêm V.A., } \\
\text { Amidan quá phát, } \\
\text { viêm mũi xuất tiết) }\end{array}$ & Không & Tổng \\
\hline $\mathrm{n}$ & 126 & 350 & 476 \\
\hline$\%$ & 26,47 & 73,53 & 100 \\
\hline
\end{tabular}

Nhận xét: tỉ lệ trẻ mắc các bệnh mũi họng mạn tính là $26,47 \%$; tỉ lệ này cũng phù hợp với tỉ lệ các bệnh lý mũi họng đặc biệt là V.A và amidan mô tả trong y vắn

3.2. Tương quan giữa tỉ lệ bệnh và các yếu tố nguy cơ

Bảng 6: Tương quan giữa yêu tố giới và tỉ lệ bệnh

\begin{tabular}{|c|c|c|c|c|}
\hline \multicolumn{2}{|c|}{} & \multicolumn{2}{c|}{ Giới } & \multirow{2}{*}{ Tổng } \\
\cline { 3 - 5 } \multicolumn{2}{|c|}{} & Nam & Nữ & \\
\hline \multirow{2}{*}{$\begin{array}{l}\text { Viềm } \\
\text { tai }\end{array}$} & Không & 254 & 202 & 456 \\
\cline { 2 - 5 } & Có & 18 & 2 & 20 \\
\hline \multicolumn{2}{|c|}{ Tống } & 272 & 204 & 476 \\
\hline
\end{tabular}

$\mathrm{p}<0,01, \mathrm{r}=0,139, \mathrm{RR}=6,75$

Nhận xét: Tỉ lệ bệnh ở giới nam cao hơn giới nữ có ý nghĩa thống kê, kết quả này cũng tương tự nư trong nghiên cứu của Nguyễn Thị Hoài An $(\mathrm{OR}=1,22)$. Chưa có bằng chứng khoa học nào chứng được nguyên nhân của sự khác biệt này. Một só nghiên cứu nhận thây sự suy giảm của IgG2 ở niêm mạc đường hô hấp ở trẻ nam so với trẻ nữ ở độ tuổi từ 2 đến 7 tuổi, tuy nhiên vẫn cần nhiều bằng chứng hơn để xác định xem đây có phải căn nguyên dẩn đến sự khác biệt về tỉ lệ bênh hay không.

Bảng 7: Tương quan giữa yếu tố tuổi và tỉ lệ bệnh

\begin{tabular}{|c|c|c|c|c|}
\hline \multicolumn{2}{|c|}{} & \multicolumn{2}{|c|}{ Nhóm tuối } & \multirow{2}{*}{ Tổng } \\
\cline { 3 - 4 } \multicolumn{2}{|c|}{$\begin{array}{c}\text { Dưới 3 } \\
\text { tuổi }\end{array}$} & $\begin{array}{c}\text { Trên } 3 \\
\text { tuổi }\end{array}$ & \\
\hline $\begin{array}{c}\text { Viêm } \\
\text { tai }\end{array}$ & Không & 240 & 216 & 456 \\
\hline \multicolumn{2}{|c|}{ Cống } & 16 & 4 & 20 \\
\hline \multicolumn{2}{|c|}{$\mathrm{p}<0,05 ; r=0,11 ;$} & 256 & 220 & 476 \\
\hline
\end{tabular}

Nhận xét: Tỉ lệ bệnh ở nhóm tuổi dưới 3 tuổi cao hớn so với nhóm trên 3 tuổi, sự khác biệt này là cóý nghĩa thống kê. Tác giả Nguyễn Thị Hoài An khi nghiên cứu tỉ lệ bệnh ở trẻ em cũng cho kết quả tương tự (ỉ lệ mắc ở nhóm nhà trẻ là $12,09 \%$ cao hơn nhóm mấu giáo là $8,98 \%$ ).

Bảng 8: Tương quan giứa yếu tố số người cùng chung sống và tỉ lệ bệnh

\begin{tabular}{|c|c|c|c|}
\hline & \multicolumn{2}{|c|}{$\begin{array}{l}\text { Số người trong } \\
\text { gia đình }\end{array}$} & \multirow[b]{2}{*}{ Tổng } \\
\hline & $\begin{array}{c}\leq 4 \\
\text { người }\end{array}$ & $\begin{array}{c}>4 \\
\text { người }\end{array}$ & \\
\hline \multirow{2}{*}{ Viêm tai } & 422 & 34 & 456 \\
\hline & 14 & 6 & 20 \\
\hline Tống & 436 & 40 & 476 \\
\hline
\end{tabular}

$\mathrm{p}<0,05, \mathrm{r}=0,163 ; \mathrm{RR}=4,67$

Nhận xét: trẻ chung sống chung gia đình càng đông ngườ thì tỉ lệ mắc bệnh càng cao, điêu này phù hợp với thực tế là gia đình càng đông người thì nguy cơ nhiễm các bệnh nhiễm trùng đường hô hấp càng cao hơn, từ đó nguy cơ mắc bệnh viêm tai giữa cũng gia tăng.

Bảng 9: Tương quan giữa yếu tố tiền sử sinh và tì lệ bệnh

\begin{tabular}{|c|c|c|c|}
\hline & \multicolumn{2}{|c|}{ Tiền sử sinh } & \multirow[b]{2}{*}{ Tổng } \\
\hline & $\begin{array}{l}\text { Đủ } \\
\text { tháng }\end{array}$ & $\begin{array}{l}\text { Thiếu } \\
\text { tháng }\end{array}$ & \\
\hline \begin{tabular}{l|l|} 
Viêm tai Không \\
\end{tabular} & 446 & 10 & 456 \\
\hline Có & 18 & 2 & 20 \\
\hline Tống & 464 & 12 & 476 \\
\hline
\end{tabular}

$\mathrm{p}>0,05$

Nhận xét: Không có mối tương quan giữa về tỉ lệ bệnh và tiền sử sinh.

Bảng 10: Tương quan giữa yêu tố cân nặng khi sinh và tí lệ bệnh

\begin{tabular}{|c|c|c|c|}
\hline & Cân năn & khi sinh & \\
\hline & $<2,8 \mathrm{~kg}$ & $\geq 2,8 \mathrm{~kg}$ & $10 \mathrm{r}$ \\
\hline Viêm tai Không & 52 & 404 & 456 \\
\hline
\end{tabular}




\begin{tabular}{|c|c|c|c|c|}
\hline Có & 8 & 12 & 20 \\
\hline Tống & $\mathbf{6 0}$ & $\mathbf{4 1 6}$ & $\mathbf{4 7 6}$ \\
\hline
\end{tabular}

Nhận xét: có mối liên quan giữa tỉ lệ mắc bệnh và căn nặng khi sinh, trẻ sinh nhẹ cân có nguy cơ mắc bệnh cao hơn.

Bảng 11: Tương quan giữa yếu tố nuôi dưỡng 6 tháng đầu đời và tỉ lể bệnh

\begin{tabular}{|c|c|c|c|c|}
\hline & \multicolumn{2}{|c|}{$\begin{array}{l}\text { Nuôi dưỡng } 6 \text { tháng } \\
\text { đâuu đời }\end{array}$} & \multirow{2}{*}{ Tổng } \\
\hline & & $\begin{array}{l}\text { Sữa mè } \\
\text { hoàn toần }\end{array}$ & $\begin{array}{l}\text { Sừa ngoài } \\
\text { hoặc cả hai }\end{array}$ & \\
\hline \multirow{2}{*}{$\begin{array}{c}\text { Viêm } \\
\text { tai }\end{array}$} & Không & 368 & 88 & 456 \\
\hline & Có & 14 & 6 & 20 \\
\hline \multicolumn{2}{|c|}{ Tống } & 382 & 94 & 476 \\
\hline
\end{tabular}

$\mathrm{p}>0,05$

Nhận xét: Nhiều công trình nghiên cứu cho thây bú sữa mẹ hoàn toàn trong 6 tháng đầu làm giảm nguy cơ mắc các bệnh đường hô hấp trên trong đó có viêm tai giữa. Trong nghiên cứu này, chúng tôi không thây có sự khác biệt về tỉ lệ bệnh giữa hai nhóm trẻ được nuôi dưởng hoàn toàn bằng sữa me trong 6 tháng đầu đời với nhóm còn lại, điều này có thể do cỡ mẫu nghiên cứu chưa đủ lớn để đại diện cho quần thể.

Bảng 12: Tương quan giữa yếu tố tiền sử bênh dị ứng và tỉ lê bênh

\begin{tabular}{|c|c|c|c|c|}
\hline & \multicolumn{2}{|c|}{ Tiên sử bênh dị ứng } & \multirow{2}{*}{ Tổng } \\
\hline & & Không & Có & \\
\hline Viêm & Không & 388 & 68 & 456 \\
\hline tai & Có & 16 & 4 & 20 \\
\hline \multicolumn{2}{|c|}{ Tống } & 404 & 72 & 476 \\
\hline
\end{tabular}

Nhẩn xét: trong nghiên cứu này không thây có sự khác biệt về tỉ lệ bệnh giữa hai nhóm trẻ có tiền sử bệnh dị ứng (mề đay, viêm kết mạc dị ứng, hen phế quản...) với nhóm còn lại.

Bảng 13: Tương quan giữa yếu tố tân suất tái phát viêm mữi họng và tỉ lệ bệnh

\begin{tabular}{|l|c|c|c|c|}
\hline \multicolumn{2}{|c|}{} & \multicolumn{2}{|c|}{$\begin{array}{c}\text { Tân suất viêm mữi } \\
\text { họng }\end{array}$} & \multirow{2}{*}{ Tổng } \\
\cline { 2 - 4 } \multicolumn{2}{|c|}{$\begin{array}{c}\text { Dưới 2 2 } \\
\text { tháng/lần }\end{array}$} & $\begin{array}{c}\text { Trên 2 } \\
\text { tháng/lần }\end{array}$ & \\
\hline \multirow{2}{*}{$\begin{array}{c}\text { Viêm } \\
\text { tai }\end{array}$} & Không & 144 & 312 & 456 \\
\cline { 2 - 4 } & Có & 16 & 4 & 20 \\
\hline \multicolumn{2}{|c|}{ Tống } & $\mathbf{1 6 0}$ & $\mathbf{3 1 6}$ & $\mathbf{4 7 6}$ \\
\hline \multicolumn{2}{|c|}{$\mathrm{p}<0,01 ; \mathrm{r}=0,206 ; \mathrm{RR}=7,9$}
\end{tabular}

Nhận xét: có mối liên quan giữa tỉ lệ mắc bệnh và tần suất tái phát viêm mũi họng, trẻ càng hay tái phát viêm mũi họng thì có nguy cơ mắc bệnh cao càng cao. Sự tương quan này là phù hợp với sinh bệnh học của các bệnh lý viêm tai giữa, trong đó các nhiễm trùng vùng mũi họng là căn nguyên chính của bệnh.
Bảng 14: Tương quan giữa yếu tồ mắc bệnh lý mưi họng mạn tính và ti lệ bệnh

\begin{tabular}{|c|c|c|c|c|}
\hline & \multicolumn{2}{|c|}{$\begin{array}{l}\text { Bệnh mũi họng } \\
\text { (Viếm V.A - Amiđan } \\
\text { quá phát, viêm mưi } \\
\text { xuất tiết...) }\end{array}$} & \multirow[t]{2}{*}{ Tổng } \\
\hline & & Không & Có & \\
\hline & Không & 348 & 108 & 456 \\
\hline & Có & 2 & 18 & 20 \\
\hline & Tống & 350 & 126 & 476 \\
\hline
\end{tabular}

Nhân xét: Bênh lý V.A quá phát, amiđan quá phát dược xem là căn nguyên chính của bệnh lý viêm tai giữa. Các tình trạng này ảnh hưởng trực tiếp dẫn đến rối loạn chức năng vòi tai, từ đó gây ra các tình trạng bệnh lý khác nhau của tai giữa mà đăc biệt là viêm tai ứ dịch. Do đó, tỉ lệ viêm tai ứ dịch ở nhóm trẻ mắc các bệnh lý này cao hơn là điều phù hợp.

\section{KẾT LUẬN}

Viêm tai ứ dịch là một tình trạng bệnh lý thường gặp ở trẻ em lứa tuổinhà trẻ, mấu giáo $(4,2 \%)$. Các yếu tố nguy cơ có liên quan đến việc làm gia tăng tỉ lệ mắc bệnh là giới nam, sinh nhe cân (dưới 2,8kg), trẻ nhỏ dưới 3 tuổi, môi trường gia đình đông người, thường xuyên tái phát viêm mũi họng và mắc các bệnh V.A Amiđan quá phát. Trong phạm vi nghiên cứu chưa thây sự tương quan về thứ tự sinh, tiền sử nuôi dưỡng bằng sữa mẹ, tiền sử dị ứng với tỉ lệ mắc bênh.

\section{TÀI LIẸU THAM KHẢO}

1. Ngưyễn Thị Hoài An, Nguyễn Hoàng Sơn (2003), Ảnh hưởng của nhiếm khuẩn hô hấp trên tới viêm tai giữa ứ dịch / - Y học thực hành - Năm 2003, số 3, tập 445, tr. 5-7.

2. Nguyê̂n Thị Hoài An và cs (2003), Nghiên cứu đạc điểm dịch tể học viêm tai giữa ứ dịch ở trẻ em phường Trung Tự và một vài phường khác thuộc Luân án tiến sỹ y hoc, tr 1: 142.

3. Nguyển Thành Chung (1999), Nghiên cứu đặc điêm lâm sàng và kết quả điêu trị bệnh viêm tai ứ dịch tại viện tai mũi họng. Luận án thạc sĩ y học, tr: $1: 71$.

4. Midgley EJ, Dewwey C, Pryce K, Maw AR (2000), The Frequency of otitis media with effusion in British pre-school children: a guide for treatment. Clin-Otolaryngol, Dec, pp: 91:485.

5. Homoe P. (2001), Otitis media in Greenland. Studies on historical, epidemiological, microbiological, and immunological aspects. Int J Circumpolar Health. 2001;60 Suppl 2:1-54.

6. Narcy $P$, Bobin $S$, Manach $Y$ (1996), Otites séro-muqueuses. EMC.

7. Pukander J, Luotonen J, Timonen M, Karma P.(1985), Risk factors affecting the occurrence of acute otitis media among 2-3-year-old urban 
children. Acta Otolaryngol. 1985 Sep-Oct;100(34):260-5.

8. Rovers $M M^{1}$, Numans $M E$, Langenbach $E_{\text {, }}$ Grobbee DE, Verheij TJ, Schilder AG. (2008),
Is pacifier use a risk factor for acute otitis media? A dynamic cohort study. Fam Pract. 2008 Aug;25(4):233-6. doi: 10.1093/fampra/cmn030. Epub 2008 Jun 17.

\title{
VAI TRÒ CỦA HÚT HUYẾT KHỐI TRONG CAN THIỆP NHỒI MÁU THÂN CẤP NHÂN MộT TRƯờNG HỢP LÂM SÀNG TẠI VIỆN TIM MẠCH VIỆT NAM
}

\author{
Nguyễn Mạnh Quân ${ }^{1,2}$, Ngô Quang Tùng1, \\ Đào Thị Ly ${ }^{1}$, Trương Thị Thanh Bình ${ }^{1}$
}

\section{TÓM TẮT}

Tổng quan: Nhồi máu thận cấp là bênh lý hiếm gặp trên lâm sàng, thường bị bỏ sót hoặc chẩn đoán nhâm lẫn với các tình trang bênh lý khác do biểu hiện lâm sàng đa dạng và không đặc hiệu. Bệnh cân được chẩn đoán sớm và điều trị để tránh làm ảnh hưởng tới chức năng thận. Hiện nay, chưa có khuyến cáo rõ ràng về điêu trị tối ưu cho nhồi máu thận cấp. Can thiệp hút huyết khối qua đường ống thông kèm điêu trị nội khoa phối hợp có thể là một lựa chọn trong chiến lược điêu trị bệnh nhân nhồi máu thân cấp. Phương pháp: Báo cáo ca lâm sang. Kết quả: Chúng tôi báo cáo ca lâm sàng hiếm gặp tại Viện Tim Mạch, Bệnh viện Bạch Mai. Bệnh nhân nam, 34 tuổi nhâp viện vì đau vùng hông lưng trái với huyết khối cấp tính gây tắc nhánh cực trên động mạch thận trái, được chẩn đoán và điều tri kip thời và cho kết quá điều trị tốt. Kết luận: Nhồi máu thận cấp là một bệnh không phổ biến và dễ bị bỏ sót. Việc chọn lựa phướng pháp điều trị phụ thuộc vào từng trường hợp cụ thể.

Tư khoá: Nhồi máu thận cấp, hút huyểt khối.

\section{SUMMARY}

ROLE OF PERCUTANEOUS THROMBECTOMY IN INTERVENTION OF ACUTE RENAL INFARCTION THROUGH A CLINICAL CASE IN VIETNAM NATIONAL HEART INSTITUTE

Background: Acute renal infarction is a rare clinical condition that is often overlooked or misdiagnosed with other medical conditions due to diverse and nonspecific clinical manifestations. The disease needs to be diagnosed early and treated to avoid affecting kidney function. Currently, there are no clear recommendations for optimal treatment for acute renal infarction. Interventional catheter thrombectomy with combined medical therapy may be an option in the treatment strategy of patients with acute renal failure. Methods: A case report. Result: We report a rare clinical case at the Vietnam Heart Institute, Bach Mai Hospital. A 34-years-old male patient was

\footnotetext{
${ }^{1}$ Viện Tim mạch Việt Nam - Bệnh viện Bạch Mai ${ }^{2}$ Trường Đại học Y Dước - Đại học Quốc gia Hà Nội Chịu trách nhiệm chính: Nguyễn Mạnh Quân Email: quannttm@gmail.com Ngày nhận bài: 13.9.2021
}

Ngày phản biện khoa học: 11.11.2021

Ngày duyệt bài: 19.11.2021 admitted to the hospital because of left flank pain with acute thrombosis causing occlusion of the left superior renal artery, which was diagnosed and treated promptly and gave good results. Conclusion: Acute renal infarction is an uncommon and easily missed disease. The choice of treatment method depends on the individual case.

Keywords: Acute renal infarction, thrombectomy

\section{I. ĐĂT VẤN ĐỀ}

Nhồi máu thận cấp là một tình trạng bệnh lý hiếm gặp trên lâm sàng, với tỷ lệ dao động từ 0,7 tới $1,4 \%$ số ca nhập viện khoa cấp cứu vì đau bụng tại Mỹ. Biểu hiện lâm sàng đa dạng, không đặc hiệu làm cho nhồi máu thận cấp thường bị bỏ sót, chẩn đoán muộn hoặc chẩn đoán nhầm lẫn với cơn đau quặn thận và các nguyên nhân gây đau bụng khác, làm ảnh hưởng, thậm chí mất hoàn toàn chức năng thận. Hiện nay, chưa có những khuyến cáo thật sự rõ ràng về lựa chọn điều trị cho nhồi máu thận, chủ yếu là tùy theo kinh nghiệm và khả năng của từng trung tâm. Tuy nhiên, có 3 phương pháp điều trị chủ yếu là: Thuốc chống đông; Can thiệp mạch qua da và Phẫu thuật.

Trong bài viết này, chúng tôi báo cáo về một trường hợp bệnh nhân nhồi máu thận được can thiệp hút huyết khối qua đường ống thông, tiến hành tại Viện Tim Mạch, Bệnh Viện Bạch Mai và bảo tồn được chức nằng thận.

\section{CA LÂM SÀNG}

Bệnh nhân nam, 34 tuổi, tiền sử hút thuốc lá 10 bao/năm, ngoài ra chưa phát hiện bệnh lý gì khác. Bệnh nhân đau vùng hông lưng bên trái dữ dội cách nhập viện 20 tiếng và được chụp CTScanner chẩn đoán: Nhồi máu thận do tắc nhánh động mạch cực trên thận trái.

Tình trạng lúc vào viện: Bệnh nhân tỉnh, còn đau hổng lưng trái âm ỉ, có lúc đau cơn nhiều hơn. Bệnh nhân không sốt, không khó thở.

Khám lâm sàng: Bụng mềm, ấn tức vùng mạn sườn trái, không có phản ứng thành bụng, Tim đều 70 chu kỳ/ phút, phổi không rales, gan 